\title{
Fault detection and isolation in a photovoltaic system
}

\author{
M. Muñoz ${ }^{1}$, A. Correcher ${ }^{2}$, E. Ariza ${ }^{3}$, E. García ${ }^{2}$ and F. Ibañez ${ }^{3}$ \\ ${ }^{1}$ Grupo de Automática Industrial, Universidad del Cauca, \\ Popayán (Colombia) \\ email: mamunoz@unicauca.edu.co \\ ${ }^{2}$ Instituto de Automática e Informática Industrial, Universitat Politècnica de València, \\ Camino de Vera Street, s/n, 46022, Valencia, (Spain). \\ email: ancorsal@upv.es, egarciam@isa.upv.es \\ ${ }^{3}$ Instituto de Ingeniería Energética, Universitat Politècnica de València, \\ Camino de Vera Street, s/n, 46022, Valencia, (Spain) \\ email: helarcha@upv.es, fibanez@eln.upv.es
}

\begin{abstract}
This paper presents a fault detection and isolation method based on identification applied to a PV system. The process has been carried out by analyzing data from a real PV installation coupled with a grid-tied monophasic inverter.
\end{abstract}

\section{Key words}

Fault detection, photovoltaic system, Petri nets.

\section{Introduction}

Photovoltaic (PV) power generation has great importance as an alternative to conventional power sources; PV installations (in scales ranging from domestic uses to large solar farms) involves a significant investment that should be cared to preserve its safety and profitability. However a PV array can keep working in a fault state as a seeming normal behavior with power losses. In this case, when the fault state holds, permanent damages or premature aging in components could happen [1]. Therefore, PV fault diagnosis becomes important to performing fast maintenance and to improving power generation.

Most fault diagnosis techniques in PV systems are based on a model. These models usually start from electrical circuit equations as functions of irradiance and temperature to create a single solar cell, solar module model. The goal is obtaining an electric characterization [2], [3].

Some improvements on these classical analytical models increase their accuracy as: in [4] the authors consider miscellaneous power losses; in [5] the authors use weather satellite and ground weather stations data to feed the model simulations. Once obtained the model, real and simulated data are compared and the differences are analyzed. Another methods measure the PV system in normal conditions, after creates a real fault event and analyses its effects; this information is used by [6], [7], [8], [9] to set up correlations between a known fault and the output signals, which are the basis for fault diagnosis. In [10], [11], [12], [13] the information is used in artificial intelligence or computational tools; these methods have reported high precision to detect and insulate fault events previously learned, but they need a training.

Regarding to large scale PV farms, in [14] the authors uses a Time Domain Reflectometry technique; a step voltage is introduced in a test electrical line, as a radar, the response is monitored by an oscilloscope to know type and localization fault. In [15], [16] use thermography and digital image processing to find hot spots and aging checking; these methods are accuracy but need fieldwork to recollect, analyze or record information, being less practical in large PV farms.

The methods mentioned above need wide technology knowledge and they can only diagnose faults included in the model. This work proposes a fault diagnosis method that works without fault models, so it could detect any abnormal behavior.

The main idea is identifying a normal working model of the PV system to compare real time data with the evolution of the identified model. Therefore, any deviation between prediction and observation implies necessarily a fault in the system.

The identified model is accurate and complete because the identification algorithm includes normal behavior signals and statistical stopping criteria to model stochastic processes.

The paper is organized as follows: Section 2 describes the fault detection and isolation process; in section 3 is 
applied the fault detection method to PV system; finally, the concluding remarks are shown in section 4 .

\section{Fault Detection and Isolation process}

PV fault detection is carried out without any previous model and it is based on the language theory and on Petri Nets $(\mathrm{PN})$.

A Petri net is a directed bipartite graph. It consists of two components: a net structure and an initial marking. A net (structure) contains two sorts of nodes: places and transitions. There are directed arcs from places to transitions and directed arcs from transitions to places in a net. Places are graphically represented by circles and transitions by boxes or bars. [18]

The diagnoser construction has two phases. First phase is the identification of the normal behavior, which results in a Stochastic Timed Interpreted Petri Net (st-IPN) generating the observed language, $\mathcal{L}^{N}$, based on the identification algorithm proposed in [17].

\section{A. Identification}

At the identification phase, input and output signals are observed and transformed into events. Each event sequence creates a word which concatenation constitutes the observed system language. After a sufficient long observation, the identification algorithm builds a st-IPN able to reproduce the system language.

A st-IPN is defined as follows:

A st-IPN is a structure represented byst $Q=(Q, \Omega, \delta, O M)$, where $Q=\left(N, U_{o}, Y, \lambda, \varphi\right)$ is an IPN, $N=\left(P, T R, M_{0}\right)$ is a Petri Net; $(P$ is the set of places, TR is the set of transitions). $U_{o}=\left\{u_{0}, \ldots, u_{\mid 2^{m_{o \mid-1}}}\right\}$ is the observable binary input set, $u_{s}$ is an input symbol and $m_{o}$ is the number of observable inputs; $Y=\left\{y_{0}, \ldots, y_{\left|2^{n}\right|-1}\right\}$ is the binary output set, $y_{j}$ is an output symbol and $n$ is the number of outputs. $\lambda: T R \rightarrow U_{o} \times \delta$ is a transition labeling function that assigns an input symbol and a time density function to each transition. $\varphi: R(N) \rightarrow Y / d Y$ is an output function that assigns an output symbol and the differential of output symbol $^{1}$ to each reachable marking, $\varphi$ is isomorphic over $Y / d Y . \Omega:=\left(U_{o} \times Y\right) . \delta$ is the system alphabet. $\delta:=T R \times O M \rightarrow f\left(t_{T R \times O M}\right)$ is the transition firing time density function for each $o_{o m} . O M=$ $\left\{o_{0}, \ldots, o_{n_{-} o m}\right\}$ is the set of operation modes, where $o_{o m}$ is a combination of binary external signals.

The $s t Q$ language is defined as $\mathcal{L}(s t Q)=\{s \mid s \subset \Omega\}$, where $s=\omega^{0}, \ldots, \omega^{k}$ is a timed compound event sequence, with $\omega^{i}=\left(u_{s} y_{j}\right) t^{e v}$; where $\left(u_{s} y_{j}\right)$ is a symbol that concatenates an input signals and an output signals at every instant $\tau_{i}$; (I/O symbol), this symbol is a compound

${ }^{1} d Y$ is the difference between current $y_{j}$ and previous $y_{j}$; so $d Y$ possible values are: $0 \times 0 \rightarrow 0 ; 0 \times 1 \rightarrow 1 ; 1 \times 0 \rightarrow$ $-1 ; 1 \times 1 \rightarrow 0$. event and $t^{e v}$ is the elapsed time between two consecutive events; being $u_{s}$ a binary representation of $s$, s stands for the input symbol at time $\tau_{i}$ and $y_{j}$ is a binary representation of $j, j$ stands for the output symbol at time $\tau_{i}$

\section{B. Diagnosis}

The diagnoser is a modification of the identified a st-IPN. In order to manage several fault models as well as the normal working mode, the diagnoser includes colored tokens, so the diagnoser is a: "Stochastic Timed Interpreted Colored Petri Net to Diagnosis" (st-DICPN).

The set of places is partitioned into $P=P_{L N} \cup P_{V F} \cup P_{I F}$ where $P_{L N}$ represents the set of latent nestling places, that is, places with nominal behavior in which a fault can happen, $P_{V F}$ is the set of places that verify the detected fault; $P_{I F}$ is a place that counts the identified faults.

The set of transitions is partitioned into $T R=T R_{N} U$ $T R_{F}$ where $T R_{N}$ represents the set of normal transitions that are fired following the normal language and $T R_{F}$ represents the set of fault transitions whose size can be increased each time a fault event is detected, they fire when a fault $f_{d f}$ is detected.

The set of color classes is $C=\{$ Behavior, $I F\}$, where Behavior $=\left\{\langle N\rangle,\left\langle(l, q) g f_{g f}\right\rangle\right\},\langle N\rangle \quad$ is the normal token, $\left\langle(l, q) g f_{g f}\right\rangle$ is the generic fault token, respectively, $l$ stands for the subsystem, $q$ stands for the place and the subscripts $g f$ is a fault identification index. $I F=\{\langle$ Integer $\rangle$.

The detection task is carried out by comparing the current event trace, $t$, with $\mathcal{L}^{N}$. If $t \notin \mathcal{L}^{N}$; a timed fault event has been detected. The algorithm creates a language model recognizer for this new situation and $t$ is considered as part of a fault language, $\mathcal{L}^{f_{i}}$.

When a fault has been detected, the structure of the diagnoser allows the isolation and identification of the fault. Therefore, a new fault trace of $\mathcal{L}^{f_{i}}$ is learned. So, the diagnosis skills of the diagnoser grow over time.

Fig. 1 shows a diagnoser example for a process.

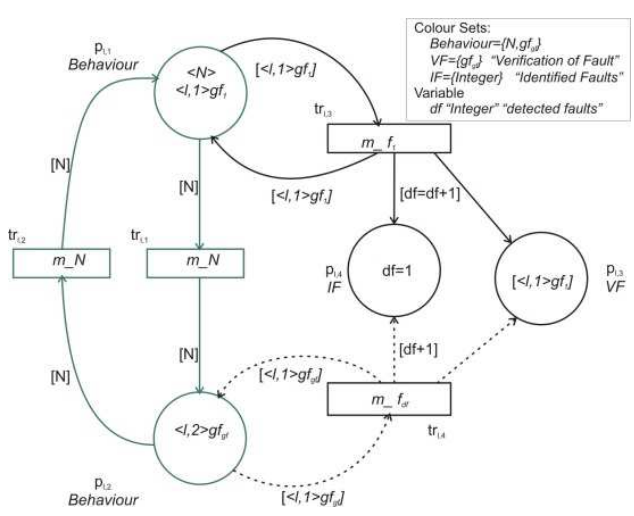

Fig. 1 st-DICPN example. 
The part of the st-DICPN (Fig. 1) in green colour represents the normal behavior which is identified on-line from the observed legal sequences. The part of the net in black colour represents the identified fault behavior by means of applying the diagnostic algorithm. Arcs with black dashed lines are transformed into continuous lines when a fault is detected in the previous place and a fault transition fire in fault mode.

\section{PV System fault diagnosis}

The PV system is a real running installation coupled with a grid-tied monophasic inverter, extra information as solar radiance and surface temperatures, is provided by a weather sensor. ¡Error! No se encuentra el origen de la referencia. shows the PV generator scheme and the signals to be considered in this work.

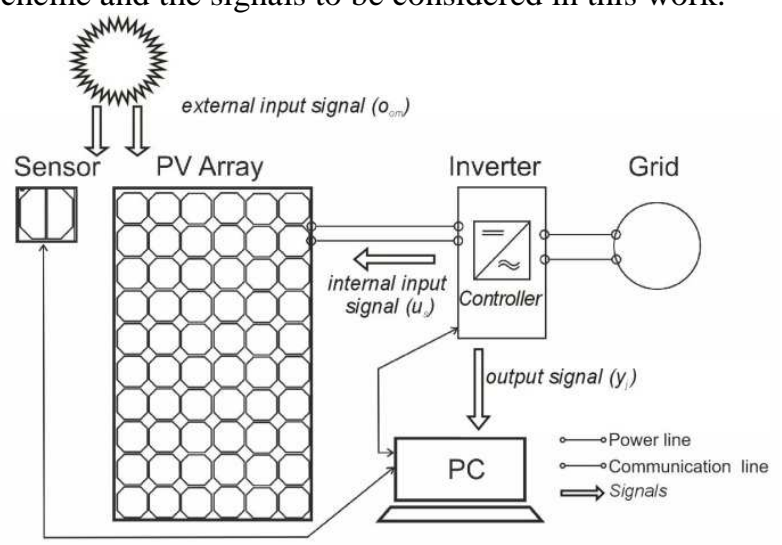

Fig. 2. PV Generator Scheme - power and communications.

Signals to consider are: external input signal: the solar radiation $(\mathrm{W} / \mathrm{m} 2)$; internal input signal: reference voltage $(\mathrm{V})$; the system outputs: DC power (W), current (A), and cell surface temperature $\left({ }^{\circ} \mathrm{C}\right)$.

\section{¡Error! No se encuentra el origen de la} referencia. shows electrical characteristics of the PV array.

Table I. - PV Array electric characteristics

\begin{tabular}{|l|l|l|l|}
\hline $\begin{array}{l}\text { Short Circuit Intensity } \\
\left(\mathrm{I}_{\mathrm{sc}}\right)\end{array}$ & $4,85 \mathrm{~A}$ & $\begin{array}{l}\text { Intensity } \\
\text { Maximum }\left(\mathrm{I}_{\mathrm{Max}}\right)\end{array}$ & $4,39 \mathrm{~A}$ \\
\hline $\begin{array}{l}\text { Open Circuit Voltage } \\
\left(\mathrm{V}_{\mathrm{oc}}\right)\end{array}$ & $445,2 \mathrm{~V}$ & $\begin{array}{l}\text { Voltage } \\
\text { Maximun }\left(\mathrm{V}_{\mathrm{Max}}\right)\end{array}$ & $354 \mathrm{~V}$ \\
\hline $\begin{array}{l}\text { Power Maximun } \\
\left(\mathrm{P}_{\text {Max }}\right)\end{array}$ & $2,500 \mathrm{~kW}$ & & \\
\hline
\end{tabular}

Identification and monitoring data are read each $100 \mathrm{~ms}$ and the instant values are saved each one minute.

The system identification algorithm [17] works on-line and it requires binary signals.

Because the system works with continuous signals, a thresholding is needed to get the values. This process establishes operating ranges according to prior knowledge of the system performance. It is shown in ¡Error! No se encuentra el origen de la referencia..
An event from the PV system is defined as $\omega^{i}=$ $\left(u_{s} y_{j}\right) t^{e v}$ for the signals considered in $i$ Error! No se encuentra el origen de la referencia., where $u_{s}$ is a binary vector that represents the reference voltage range states; $y_{j}$ is a binary vector representing the state of each range slot of the output signals.

For example, if the reference voltage is between $360-$ 599 , then the second range slot is active ([00010]). This binary array represents the binary number of 2 ; its event representation will be $u_{2}$. If the DC power is between $1.200-1.800$ watts, [0010], the current is between 0,002 - 0,6 A, [0010] and the cell surface temperature is between $0-16{ }^{\circ} \mathrm{C},[1000]$, then, concatenating the input signals, the input vector is [001001001000]. This binary number is 584 , therefore its event representation will be $\mathrm{y}_{584}$. The input/output event will be $\omega^{i}=\left(u_{2} y_{584}\right) \cdot t^{e v}$; being $t^{e v}$ the elapsed time between $\omega^{i-1}$ and $\omega^{i}$.

Table II. - Operating Ranges

\begin{tabular}{|l|c|}
\hline \multicolumn{1}{|c|}{ Signal } & Range \\
\hline \multirow{4}{*}{ Solar Radiation (W/m2) } & $>900$ \\
\cline { 2 - 2 } & $200-900$ \\
\cline { 2 - 2 } & $20-200$ \\
\hline \multirow{4}{*}{ Reference Voltage (V) } & $0-20$ \\
\cline { 2 - 2 } & $\geq 600$ \\
\cline { 2 - 2 } & $360-599$ \\
\cline { 2 - 2 } & $300-360$ \\
\hline \multirow{4}{*}{ DC Power (W) } & $180-300$ \\
\cline { 2 - 2 } & $0-180$ \\
\cline { 2 - 2 } Current (A) & $1.800-2.500$ \\
\cline { 2 - 2 } & $1.200-1.800$ \\
\cline { 2 - 2 } & $600-1.200$ \\
\cline { 2 - 2 } & $0-600$ \\
\cline { 2 - 2 } & $3,8-4,39$ \\
\hline Cell Surface Temperature & $0,6-3,8$ \\
\cline { 2 - 2 }$\left({ }^{\circ} \mathrm{C}\right)$ & $0,002-0,6$ \\
\cline { 2 - 2 } & $0-0,002$ \\
\cline { 2 - 2 } & $>60$ \\
\hline
\end{tabular}

The solar radiation is an external input signal. This signal defines an operating mode in the $\mathrm{PV}, \mathrm{O}_{\mathrm{om}}$. Operation modes also needs a thresholding. As an example, $o_{2}=[0100]$ means that the solar radiation is between $200-900(\mathrm{~W} / \mathrm{m} 2)$.

We have feeded the identification algorithm with fault free data feeding and the result is a st-IPN representing the normal behavior of the system. ¿Error! No se encuentra el origen de la referencia. shows the st-IPN structure. $^{2}$

¡Error! No se encuentra el origen de la referencia. shows the st-IPN identified. Columns show (in order): transition number, input required, input place, initial reading, output place, expected reading and expected

\footnotetext{
${ }^{2} \mathrm{dY}$ is omitted to improve the readability.
} 
probability distribution for the time the transition fires. For example, first line defines the transition 1, when this transition is triggered by an $u_{1}$ input signal, the system goes from state 0 which has an output signal $y_{1160}$ to state 1 which has an output signal $y_{1096}$. This transition fires with an average time of $17,5 \mathrm{~min}$. if solar radiation is over

Table III. Structure st-IPN
$900(\mathrm{~W} / \mathrm{m} 2)\left(o_{1}\right)$ or $56 \mathrm{~min}$. if solar radiation is between $200-900(\mathrm{~W} / \mathrm{m} 2)\left(o_{2}\right)$.

\begin{tabular}{|c|c|c|c|c|c|c|c|c|c|}
\hline \multirow{2}{*}{$\frac{\text { Transition }}{N r}$} & \multirow{2}{*}{$\begin{array}{c}\text { Input } \\
\text { Function }\end{array}$} & \multicolumn{2}{|c|}{ pre } & \multicolumn{2}{|c|}{ post } & \multicolumn{4}{|c|}{ Density Function } \\
\hline & & state & $\begin{array}{c}\text { Output } \\
\text { Function }\end{array}$ & state & $\begin{array}{c}\text { Output } \\
\text { Function }\end{array}$ & $o_{1}$ & $\mathrm{O}_{2}$ & $o_{4}$ & $o_{8}$ \\
\hline 1 & $u_{1}$ & 0 & $y_{1160}$ & 1 & $y_{1096}$ & $\mathrm{~N}(17,5 ; 1,21)$ & $\mathrm{N}(56,1 ; 5,2)$ & & \\
\hline 2 & $u_{1}$ & 1 & $y_{1096}$ & 2 & $y_{1096}$ & $\mathrm{~N}(5 ; 3,03)$ & & & \\
\hline 3 & $u_{2}$ & 2 & $y_{1096}$ & 3 & $y_{1160}$ & $\mathrm{~N}(70,8 ; 8,1)$ & $\mathrm{N}(4,25 ; 1,25)$ & & \\
\hline 4 & $u_{2}$ & 3 & $y_{1160}$ & 0 & $y_{1160}$ & & $\mathrm{~N}(7 ; 1,03)$ & & \\
\hline 5 & $u_{4}$ & 0 & $y_{1160}$ & 1 & $y_{1096}$ & & $\mathrm{~N}(1 ; 0,3)$ & & \\
\hline 6 & $u_{4}$ & 3 & $y_{1160}$ & 1 & $y_{1096}$ & & $\mathrm{~N}(3,75 ; 0,82)$ & & \\
\hline 7 & $u_{2}$ & 1 & $y_{1096}$ & 2 & $y_{1096}$ & & $\mathrm{~N}(3,6 ; 0,35)$ & & \\
\hline 8 & $u_{4}$ & 2 & $y_{1096}$ & 4 & $y_{584}$ & & $\mathrm{~N}(7,5 ; 0,15)$ & & \\
\hline 9 & $u_{4}$ & 4 & $y_{584}$ & 5 & $y_{552}$ & & $\mathrm{~N}(3,4: 0,13)$ & & \\
\hline 10 & $u_{4}$ & 5 & $y_{552}$ & 6 & $y_{548}$ & & $\mathrm{~N}(9 ; 1,25)$ & $\mathrm{N}(8 ; 2,05)$ & \\
\hline 11 & $u_{4}$ & 6 & $y_{548}$ & 7 & $y_{552}$ & & $\mathrm{~N}(12 ; 1,3)$ & $\mathrm{N}(48 ; 5,12)$ & \\
\hline 12 & $u_{4}$ & 7 & $y_{552}$ & 6 & $y_{548}$ & & $\mathrm{~N}(8,2 ; 2,3)$ & $\mathrm{N}(116 ; 5,8)$ & \\
\hline 13 & $u_{4}$ & 6 & $y_{548}$ & 8 & $y_{546}$ & & & $\mathrm{~N}(24 ; 3,01)$ & \\
\hline 14 & $u_{4}$ & 8 & $y_{546}$ & 9 & $y_{548}$ & & & $\mathrm{~N}(3 ; 0,325)$ & \\
\hline 15 & $u_{4}$ & 9 & $y_{548}$ & 10 & $y_{530}$ & & & $\mathrm{~N}(28 ; 2,04)$ & $\mathrm{N}(10 ; 2,1)$ \\
\hline 16 & $u_{4}$ & 10 & $y_{530}$ & 11 & $y_{548}$ & & & $\mathrm{~N}(20 ; 2,14)$ & \\
\hline 17 & $u_{4}$ & 11 & $y_{548}$ & 7 & $y_{552}$ & & & $\mathrm{~N}(42 ; 2,16)$ & $\mathrm{N}(11 ; 1,3)$ \\
\hline 18 & $u_{4}$ & 7 & $y_{552}$ & 12 & $y_{584}$ & & & $\mathrm{~N}(3,2 ; 0,2)$ & \\
\hline 19 & $u_{4}$ & 12 & $y_{584}$ & 5 & $y_{552}$ & & $\mathrm{~N}(63 ; 2,03)$ & $\mathrm{N}(7,5 ; 0,18)$ & \\
\hline 20 & $u_{4}$ & 5 & $y_{552}$ & 13 & $y_{552}$ & & $\mathrm{~N}(42 ; 3,04)$ & $\mathrm{N}(98 ; 4,06)$ & \\
\hline 21 & $u_{2}$ & 13 & $y_{552}$ & 6 & $y_{548}$ & & $\mathrm{~N}(5 ; 0,2)$ & $\mathrm{N}(3 ; 0,15)$ & \\
\hline 22 & $u_{4}$ & 8 & $y_{546}$ & 14 & $y_{530}$ & $\mathrm{~N}(11 ; 1)$ & & $\mathrm{N}(3 ; 0,5)$ & \\
\hline 23 & $u_{4}$ & 14 & $y_{530}$ & 15 & $y_{546}$ & & & $\mathrm{~N}(7 ; 0,01)$ & \\
\hline 24 & $u_{4}$ & 15 & $y_{546}$ & 14 & $y_{530}$ & & $\mathrm{~N}(9 ; 0,1)$ & $\mathrm{N}(13,5 ; 0.2)$ & \\
\hline 25 & $u_{4}$ & 15 & $y_{546}$ & 9 & $y_{548}$ & & $\mathrm{~N}(6,5 ; 0,2)$ & $\mathrm{N}(8,5 ; 0,3)$ & \\
\hline 26 & $u_{4}$ & 9 & $y_{548}$ & 8 & $y_{546}$ & & $\mathrm{~N}(4 ; 0,1)$ & $\mathrm{N}(23 ; 0,02)$ & \\
\hline 27 & $u_{4}$ & 9 & $y_{548}$ & 7 & $y_{552}$ & & & $\mathrm{~N}(2 ; 0,93)$ & \\
\hline 28 & $u_{4}$ & 5 & $y_{552}$ & 12 & $y_{584}$ & & & $\mathrm{~N}(3,33 ; 0,25)$ & \\
\hline 29 & $u_{4}$ & 12 & $y_{584}$ & 16 & $y_{1096}$ & & & $\mathrm{~N}(36,75 ; 3,1)$ & $\mathrm{N}(36 ; 0,1)$ \\
\hline 30 & $u_{4}$ & 16 & $y_{1096}$ & 3 & $y_{1160}$ & & & $\mathrm{~N}(15 ; 1,9)$ & \\
\hline 31 & $u_{4}$ & 3 & $y_{1160}$ & 0 & $y_{1160}$ & & & $\mathrm{~N}(1 ; 0,6)$ & \\
\hline 32 & $u_{2}$ & 0 & $y_{1160}$ & 0 & $y_{1160}$ & & & $\mathrm{~N}(23 ; 2,82)$ & \\
\hline 33 & $u_{1}$ & 1 & $y_{1096}$ & 3 & $y_{1160}$ & & & $\mathrm{~N}(3 ; 0,13)$ & \\
\hline 34 & $u_{1}$ & 3 & $y_{1160}$ & 1 & $y_{1096}$ & $\mathrm{~N}(4 ; 0,2)$ & & $\mathrm{N}(5 ; 0,55)$ & \\
\hline 35 & $u_{1}$ & 2 & $y_{1096}$ & 2 & $y_{1096}$ & $\mathrm{~N}(3,9 ; 0,1)$ & $\mathrm{N}(17,3 ; 4,1)$ & & \\
\hline 36 & $u_{4}$ & 2 & $y_{1096}$ & 2 & $y_{1096}$ & & $\mathrm{~N}(44 ; 5,5)$ & & \\
\hline 37 & $u_{2}$ & 1 & $y_{1096}$ & 3 & $y_{1160}$ & & $\mathrm{~N}(63 ; 2,5)$ & & \\
\hline 38 & $u_{2}$ & 2 & $y_{1096}$ & 17 & $y_{1064}$ & & $\mathrm{~N}(23,8 ; 2,03)$ & & \\
\hline 39 & $u_{4}$ & 17 & $y_{1064}$ & 18 & $y_{552}$ & & $\mathrm{~N}(52 ; 1)$ & & \\
\hline 40 & $u_{4}$ & 18 & $y_{552}$ & 6 & $y_{584}$ & & $\mathrm{~N}(36 ; 2,15)$ & & \\
\hline 41 & $u_{4}$ & 6 & $y_{584}$ & 19 & $y_{292}$ & & $\mathrm{~N}(17 ; 3,01)$ & & \\
\hline 42 & $u_{4}$ & 19 & $y_{292}$ & 20 & $y_{548}$ & & & $\mathrm{~N}(24,8 ; 2,05)$ & \\
\hline 43 & $u_{4}$ & 20 & $y_{548}$ & 8 & $y_{546}$ & & & $\mathrm{~N}(36 ; 4,25)$ & $\mathrm{N}(10 ; 2,2)$ \\
\hline 44 & $u_{4}$ & 15 & $y_{546}$ & 21 & $y_{290}$ & & & $\mathrm{~N}(25,1 ; 2,5)$ & \\
\hline 45 & $u_{4}$ & 21 & $y_{290}$ & 22 & $y_{274}$ & & & $\mathrm{~N}(33 ; 5,01)$ & \\
\hline 46 & $u_{4}$ & 22 & $y_{274}$ & 23 & $y_{530}$ & & & $\mathrm{~N}(14,9 ; 2,2)$ & \\
\hline 47 & $u_{4}$ & 23 & $y_{530}$ & 15 & $y_{546}$ & & $\mathrm{~N}(10 ; 1,14)$ & & \\
\hline 48 & $u_{4}$ & 12 & $y_{584}$ & 24 & $y_{648}$ & & & $\mathrm{~N}(52,2 ; 2)$ & \\
\hline 49 & $u_{4}$ & 24 & $y_{648}$ & 25 & $y_{1160}$ & & & $\mathrm{~N}(5,65 ; 0 ; 97)$ & \\
\hline 50 & $u_{2}$ & 25 & $y_{1160}$ & 0 & $y_{1160}$ & & $\mathrm{~N}(75,8 ; 4,12)$ & & \\
\hline
\end{tabular}

This st-IPN structure is identifies three system behaviors; first, the system startup, until it is stabilizes; second, the system working in maximum production and finally the power reduction. 
The system startup is shown in Fig 2, as a st-IPN. We shows its working with the evolution of the first transition. The initial state is $p_{0}$ with $\varphi\left(p_{0}\right)=$ $y_{1160} /[000000000000] ; d Y=\overrightarrow{0}$ because there is not history information of the output signals. If the solar radiation is between $20-200 \mathrm{~W} / \mathrm{m} 2\left(0_{2}\right)$ and after average time of $56,1 \mathrm{~min}$. the input changes to $u_{1}$ and the net evolves to state $p_{1}$ with $\varphi\left(p_{1}\right)=y_{1096} /[0000-11000000]$, that means that the DC power continues between $600-1.200 \mathrm{~W}$, the current changes its range and the cell surface temperature continues between $0-16{ }^{\circ} \mathrm{C}$. But if the solar radiation is $>900\left(0_{1}\right)$, the input changes to $u_{4}$ and the net evolves to state $p_{1}$, too, after average time $17,5 \mathrm{~min}$.

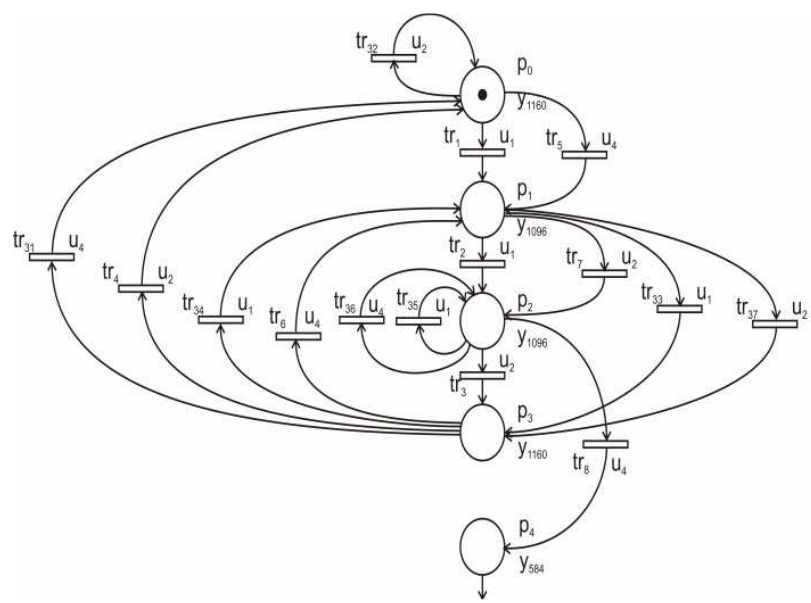

Fig. 3. st-IPN.

\section{A. On-line Monitoring}

Fault detection and isolation consists of on-line monitoring; more precisely the process consists of:

- $\quad$ Initialize the diagnoser in $\left(p_{0}\right)$, with $\varphi\left(p_{0}\right)=$ $y_{1160} / \overrightarrow{0}$.

- Observe an on-line event, $\omega^{i}$ : if $\omega^{i} \in \mathcal{L}^{N}$, then $t r_{r} \in T R_{N}$ is fires in normal mode and a normal token is placed at $m\left(p_{q}\right)=\langle N\rangle$; else, a fault trace has been detected and a new $t r_{r} \in T R_{F}$ is generated (if not exist) and it is fires in $f_{d f}$ mode, a generic fault token is reached in $m\left(p_{V F}\right)=\left\langle(l, q) g f_{g f}\right\rangle$ and other integer token is reached in $m\left(p_{I F}\right)=$ $\langle$ Integer $\rangle$. The fault has been isolated.

- $\quad$ Observe an on-line new event $\omega^{i}$.

Applying this process to the PV system, the results are shown in ¡Error! No se encuentra el origen de la referencia..

Table IV. Fault Detection and Isolation

\begin{tabular}{|c|l|l|l|c|c|l|}
\hline Fault & $\begin{array}{l}\text { Detection } \\
\text { Time } \\
(\mathrm{min})\end{array}$ & $\begin{array}{l}\text { Fault } \\
\text { Signal }\end{array}$ & State & Expected reading & $\begin{array}{l}\text { Observed } \\
\text { Reading }\end{array}$ & $\begin{array}{l}\text { Faulty } \\
\text { signal }\end{array}$ \\
\hline$f_{1}$ & 153 & Output & 4 & {$[001000101000]$} & {$[000000101000]$} & Power \\
\hline$f_{2}$ & 304 & Input & 7 & {$[00100]$} & {$[01000]$} & \\
\hline$f_{3}$ & 307 & Output & 7 & $\begin{array}{c}{[001000100100] \text { or }} \\
{[001001001000]}\end{array}$ & {$[001010001000]$} & Current \\
\hline$f_{4}$ & 586 & Output & 12 & $\begin{array}{c}{[001000101000] \text { or }} \\
{[010001001000] \text { or }} \\
{[001001001000]}\end{array}$ & {$[000001001000]$} & Power \\
\hline$f_{5}$ & 645 & Output & 24 & $\begin{array}{c}{[010010001000]} \\
{[001001001000]}\end{array}$ & $\begin{array}{l}\text { Power } \\
\text { and } \\
\text { current }\end{array}$ \\
\hline$f_{6}$ & 650 & Input & 24 & {$[00100]$} & {$[01000]$} & \\
\hline$f_{7}$ & 652 & Input & 24 & {$[00100]$} & {$[01000]$} & \\
\hline$f_{8}$ & 712 & Output & 24 & {$[010010001000]$} & {$[010001001000]$} & Current \\
\hline
\end{tabular}

Table IV summarizes the principal faults detected in the on-line monitoring of the PV system carried out by four weeks.

The detected faults are mainly due to breakdown in communication by power shutdown, line insulation or by saturation of memory buffer.

\section{B. Fault detection and isolation.}

The diagnoser finds events that are related with an unwanted behavior. They occur when the system signals are not the expected or they do not occur at the expected time.
Faults $f_{1}$ and $f_{4}$, are due to power readings outside the range; this mean that the power measurement is greater than 2.500 watts. This is not physically possible due to constraints of the inverter and can be inferred as a communication problem.

$f_{2}$, is a fault shown a change in reference voltage without previous power change, then it is a bad control order creates by the inverter.

Faults $f_{3}, f_{8}$, are faults related to lower current, that could happen by a miscommunication or by a delay in device registers updating. 
Fault $f_{5}$ is due to current and power signals fault. Two possible situations explains this. First, these behaviors are due to miscommunication in data acquiring. Second, the presence of partial shading that reduces solar radiation received by the photovoltaic generator but no in the radiation sensor or the other way round, resulting in a higher or lower power output vs. the expected power.

Faults $f_{6}$ and $f_{7}$ are faults related with voltage, they happen when there are suddenly changes in solar radiation and the Maximum Power Point Tracker algorithm oscillates for searching an optimum voltage operation. $f_{6}$ and $f_{7}$ are not a real faults, are actions to recover the normal operation not detected in the identification process.

The maximum number of faults that can be detected with this method depends on the number of signals to be measured in the system states. Therefore $\left|f_{d f}\right|=2^{n_{-} s r}$; where $n \_s r$ is the number of sensors.

\section{Conclusions}

The detection and isolation faults method presented in this paper, applied in PV systems, has advantages with respect to classical techniques, because it works without previous behavior mode. It allows to detect all kind of faults starting from to the measures of the system signals based on residuals, over deterministic models. Moreover, the computational cost is low.

The "st-DICPN" proposed detects faults by comparing the behavior observed with normal language previously identified; therefore, the ability to detect faults strongly depends on the identified model.

\section{Acknowledgement}

This work was supported by a grant from the Universidad del Cauca, reference 2.3-31.2/05 2011.

\section{References}

[1] M. A. Eltawil and Z. Zhao, "Grid-connected photovoltaic power systems: Technical and potential problemsA review," Renew. Sustain. Energy Rev., vol. 14, no. 1, pp. 112129, Enero 2010.

[2] A. Houssein, N. Heraud, I. Souleiman, and G. Pellet, "Monitoring and fault diagnosis of photovoltaic panels," in Energy Conference and Exhibition (EnergyCon), 2010 IEEE International, 2010, pp. 389-394.

[3] K.-H. Chao, S.-H. Ho, and M.-H. Wang, "Modeling and fault diagnosis of a photovoltaic system," Electr. Power Syst. Res., vol. 78, no. 1, pp. 97-105, Enero 2008.

[4] A. Chouder and S. Silvestre, "Automatic supervision and fault detection of PV systems based on power losses analysis," Energy Convers. Manag., vol. 51, no. 10, pp. 19291937, Oct. 2010.

[5] A. Drews, A. C. de Keizer, H. G. Beyer, E. Lorenz, J. Betcke, W. G. J. H. M. van Sark, W. Heydenreich, E. Wiemken, S. Stettler, P. Toggweiler, S. Bofinger, M. Schneider, G. Heilscher, and D. Heinemann, "Monitoring and remote failure detection of grid-connected PV systems based on satellite observations," Sol. Energy, vol. 81, no. 4, pp. 548-564, Abril 2007.

[6] S. K. Firth, K. J. Lomas, and S. J. Rees, "A simple model of PV system performance and its use in fault detection," Sol. Energy, vol. 84, no. 4, pp. 624-635, Abril 2010.

[7] M. Catelani, L. Ciani, L. Cristaldi, M. Faifer, M. Lazzaroni, and P. Rinaldi, "FMECA technique on photovoltaic module," in 2011 IEEE Instrumentation and Measurement Technology Conference (I2MTC), 2011, pp. 1-6.

[8] Y. Zhao, L. Yang, B. Lehman, J.-F. de Palma, J. Mosesian, and R. Lyons, "Decision tree-based fault detection and classification in solar photovoltaic arrays," in 2012 TwentySeventh Annual IEEE Applied Power Electronics Conference and Exposition (APEC), 2012, pp. 93-99.

[9] N. Gokmen, E. Karatepe, B. Celik, and S. Silvestre, "Simple diagnostic approach for determining of faulted PV modules in string based PV arrays," Sol. Energy, vol. 86, no. 11, pp. 3364-3377, Nov. 2012.

[10] K.-H. Chao, P.-Y. Chen, M.-H. Wang, and C.-T. Chen, "An Intelligent Fault Detection Method of a Photovoltaic Module Array Using Wireless Sensor Networks," Int. J. Distrib. Sens. Netw., vol. 2014, p. e540147, May 2014.

[11] S. Silvestre, A. Chouder, and E. Karatepe, "Automatic fault detection in grid connected PV systems," Sol. Energy, vol. 94, pp. 119-127, Agosto 2013.

[12] P. Ducange, M. Fazzolari, B. Lazzerini, and F. Marcelloni, "An intelligent system for detecting faults in photovoltaic fields," in 2011 11th International Conference on Intelligent Systems Design and Applications (ISDA), 2011, pp. 1341-1346.

[13] S. Syafaruddin, E. Karatepe, and T. Hiyama, "Controlling of artificial neural network for fault diagnosis of photovoltaic array," in 2011 16th International Conference on Intelligent System Application to Power Systems (ISAP), 2011, pp. 1-6.

[14] L. Schirone, F. P. Califano, U. Moschella, and U. Rocca, "Fault finding in a $1 \mathrm{MW}$ photovoltaic plant by reflectometry," in IEEE Photovoltaic Specialists Conference 1994, 1994 IEEE First World Conference on Photovoltaic Energy Conversion, 1994., Conference Record of the Twenty Fourth, 1994, vol. 1, pp. 846-849 vol.1.

[15] E. Kaplani, "Detection of Degradation Effects in Field-Aged c-Si Solar Cells through IR Thermography and Digital Image Processing," Int. J. Photoenergy, vol. 2012, p. e396792, May 2012.

[16] J. A. Tsanakas, D. Chrysostomou, P. N. Botsaris, and A. Gasteratos, "Fault diagnosis of photovoltaic modules through image processing and Canny edge detection on field thermographic measurements," Int. J. Sustain. Energy, vol. 0, no. 0, pp. 1-22, Agosto 2013.

[17] D. M. Muñoz, A. Correcher, E. García, and F. Morant, "Identification of Stochastic Timed Discrete Event Systems with st-IPN," Math. Probl. Eng., vol. 2014, p. e835312, Jul. 2014.

[18] Branislav Hrúz and MengChu Zhou, Modeling and Control of Discrete-event Dynamic Systems. London: Springer London, 2007. 